\title{
The Relational Conception of Practical Authority
}

\author{
N. P. Adams
}

In this article I articulate a new conception of practical authority based on an analysis of the relationship between authorities and subjects. When one person issues a command to another, a certain kind of relationship obtains and the commander signals that this relationship is appropriate. Most importantly, commands demand practical deference from subjects, so issuing a command to another person signals that such a demand for deference is justified. We usually do not stand in a relationship of deference to other people, let alone in a relationship where deference can be unilaterally demanded. Analyzing the conditions under which such an unusual relationship is justified illuminates the conditions for genuine (or legitimate, or justified, or de jure) practical authority. ${ }^{1}$

My analysis results in four conditions: the duty, precedence, acceptance, and trustworthiness conditions, which together constitute the relational conception of practical authority. The conditions put constraints on both parties in an authority relationship; if and only if the conditions are jointly met can one person have genuine practical authority over another person. The primary virtue of the relational analysis is that it frames the question of authority not simply in terms of the conditions on rational deference but in terms of when it is appropriate for both parties to enter a certain kind of relationship. The standing to issue commands needs justification as much as the position of deference does.

This emphasis on the authority herself grounds the most distinctive parts of the relational conception; in other respects, it builds on Joseph Raz's influential service conception. ${ }^{2}$ The uniquely relational elements of my analysis add important depth to our understanding of authority. ${ }^{3}$ Raz and much of the literature that follows him frame authority through the perspective of the subject, focusing on whether obeying an authority

\footnotetext{
${ }^{1}$ I prefer 'genuine' because, first, it is an open question how an institution's legitimacy depends on its possession of authority qua Hohfeldian power. Calling genuine authority "legitimate" obscures this question, particularly in the political context. On this distinction, see N. P. Adams, "Institutional Legitimacy," The Journal of Political Philosophy (forthcoming); Christopher W. Morris, An Essay on the Modern State (Cambridge: Cambridge University Press, 1998), ch. 4; Allen Buchanan, The Heart of Human Rights (Oxford: Oxford University Press, 2012), ch. 6. Second, understanding authority as a normative power means that one either has authority or one does not; "unjustified" possession of the power is incoherent. A claim to authority can be justified or not, but claiming is distinct from possessing. Third, 'de jure' conjures legal authority rather too closely for my broader concerns.

2 Joseph Raz, The Morality of Freedom (Oxford: Oxford University Press, 1986).

3 Others have pursued relational-in some sense-analyses of authority. Most prominently: Stephen Darwall, "Authority and Second-Personal Reasons for Acting," in Morality, Authority, and Law: Essays in SecondPersonal Ethics I (Oxford: Oxford University Press, 2013): pp. 135-150. Darwall's analysis is part of his broader theory of normative ethics and so requires many contested theoretical commitments. My approach is intentionally ecumenical to a wide range of comprehensive moral theories. Scott Hershovitz, "The Role of Authority," Philosopher's Imprint 11 (2011): pp. 1-19 incorporates relations in yet another manner.
} 
can be rational or consistent with autonomy.4 Answering these difficult questions is important for our understanding of authority. But authority, as I will argue, is robustly relational and focusing on only one party in the relationship leaves us with a one-sided understanding of authority, which in turn generates an inappropriately limited set of normative conditions on authority. Authority is about whether one person has the standing to demand deference from another, not just about when deference is rational or autonomous.

Here is the plan. In the first section I characterize the concept of authority, following Raz's rationalist approach. In section two I undertake the relational analysis. In the third section I argue for four conditions on genuine authority that can make sense of the claims intrinsic to the authority relationship articulated in section two. Finally, in section four I compare the relational conception to the service conception and apply it to institutions.

\section{Authority}

In the sense I am concerned with, authority is a Hohfeldian normative power. ${ }^{5}$ Someone with authority can change the elements of another person's normative standing (the collection of her Hohfeldian advantages and disadvantages) simply by expressing her intent that those elements change. ${ }^{6}$ We all have the power to change our own normative standing in important and decisive ways. You have a standing claim-right not to be struck but can waive that right and thereby waive others' correlative duty not to strike you, as boxers do in a boxing match. Authority is akin to having this power of self-determination over someone else.

Authorities determine how others may act and how they may be acted upon; they drastically shape the position of a person in their community and their relationships. This is a surprising power to have over someone else, to put it mildly. Authority is prima facie seriously objectionable in significant part because it involves having control over another person's normative standing in a way that our autonomy rights usually protect against.

Authority is exercised by issuing commands, which importantly require mutual recognition in order to succeed. (Here I use 'command' in the somewhat technical sense that identifies exercises of authority and so has the characteristics identified below, rather

\footnotetext{
${ }^{4}$ See Scott Shapiro, "Authority," in Jules L. Coleman, Kenneth Einar Himma, and Scott J. Shapiro (ed.), The Oxford Handbook of Jurisprudence and Philosophy of Law (Oxford: Oxford UP, 2002): pp. 382-438.

5 Wesley Newcomb Hohfeld, Fundamental Legal Conceptions as Applied to Judicial Reasoning (New Haven: Yale University Press, 1919).

${ }^{6}$ On authority as a Hohfeldian power, see Raz, The Morality of Freedom; Leslie Green, The Authority of the State (Oxford: Clarendon Press, 1988); Stephen Perry, "Political Authority and Political Obligation," in Leslie Green and Brian Leiter (ed.), Oxford Studies in Philosophy of Law Vol. 2 (Oxford: Oxford University Press, 2013): pp. 1-74. Other senses of authority, which I am not concerned with here, include authorized force and the bindingness of reasons generally.
} 
than in the broader sense of any kind of directive.) Commands involve the particular reflexive intention that is distinctive of certain kinds of illocutionary acts: the speaker accomplishes a particular act by expressing her intent to accomplish that act to the recipient and intending that the act be accomplished by the recipient's recognition of the speaker's intention.7 I could impose a duty to stop on you in a variety of ways, for example by stepping into a crosswalk. When I command you to stop, for example as a traffic cop, I express my intention to change your normative standing by imposing a duty to stop. If you accept my authority, you treat my intention as successful so you take yourself to have a duty to stop (and, under favorable conditions, therefore also form an intention to stop and stop). If you treat my utterance as a joke or a request, it fails as a command because you don't recognize my intention to bind you.

Commands (of genuine authorities) change normative standing, which in general is determined by the balance of reasons. For example, ceteris paribus the weighty reasons of others' rights and our reasons to avoid causing suffering defeat the reasons we might have to strike someone, so we have a duty not to strike them. Changes in our normative standing are the result of changes in our reasons, so the power to change another's standing with commands must be the result of some capacity to change their reasons in a unique and drastic manner. This is the basis for Raz's rationalist approach to authority, according to which commands constitute preemptive and content-independent practical reasons.

Commands constitute preemptive reasons because commands don't simply add another consideration to the balance of reasons, commands determine how the balance will go. ${ }^{8}$ This contrasts with the normal way we give others reasons, for example by request. Your boss' command to attend a meeting is very different from your coworker's request. Your coworker's request gives you a reason to attend the meeting but may very well be outweighed by your need to do other work. Your boss' command, on the other hand, preempts the other (employment-related) reasons you have and gives you an (employment) obligation to attend the meeting, even if you are very busy. The commands of authorities preempt other reasons instead of being weighed against them, so determine normative standing. Preemption captures the sense in which commands bind subjects.

Commands constitute content-independent reasons because the force of a command comes from qualities of the commander, not from qualities of the content of the command. ${ }^{9}$ When a parent exercises her parental authority and commands her child to go to bed, the child may ask why they should obey. A paradigmatic response is "Because I told you to." The parent avoids explaining the merits of a good night's sleep, instead appealing directly

\footnotetext{
7 J. L. Austin, How to Do Things with Words (Oxford: Oxford University Press, 1955); P. F. Strawson, "Intention and Convention in Speech Acts," The Philosophical Review 73 (1964): pp. 439-460.

8 This needs various qualifications, e.g. commands from authorities only bind within their jurisdiction, so may not determine the balance of a subject's reasons all things considered.

9 N. P. Adams, "In Defense of Content-Independence," Legal Theory (forthcoming).
} 
to her standing as a sufficient reason for obedience. A stranger who issued a command with the same content would not bind the child to go to bed because the stranger doesn't stand in the appropriate relationship to the child. An appeal to the qualities of the commander rather than the merits of the command is essential to authority: if subjects only acted when they judged the content of a command to be of high quality, then authority loses its value as a practice and its place in our social world. The whole idea is that the command replaces the subject's individual judgment. ${ }^{10}$

When we combine the insight that commands are illocutionary speech acts with preemption and content-independence, we get the following picture: authorities have the power to determine subjects' standing, regardless of subjects' other (in-jurisdiction) reasons, just because the authority said so, simply by conveying the intention to effect such a change. The question for any account of authority is how one person could have such dramatic and unusual control over another.

\section{The Relational Analysis}

In this section I analyze the relationship that obtains between two persons when one claims authority over another. I borrow my general methodology from some contemporary epistemology of testimony. ${ }^{11}$ On these accounts, testimony involves the particular relational act of telling to: a hearer's reasons to believe that $\mathrm{p}$ on the basis of testimony that $\mathrm{p}$ are distinct from reasons based on a mere assertion that $\mathrm{p}$. Testifying involves presenting an assertion as responding to another person's epistemic needs and putting one's reputation behind the assertion. But we rarely explicitly state that we are responding to an epistemic need or that we stand behind our assertion. Instead we find these elements of testimony in the signals and implicit claims that structure the testimonial relationship. ${ }^{12}$ As Edward Hinchman writes, "We cannot understand the nature of telling without understanding how it functions in the real world of human relations."13

My telling you that $\mathrm{p}$ signals that I am meeting your epistemic needs because it would violate various implicit norms of interpretive charity and conversational implicature

\footnotetext{
${ }^{10}$ Raz, The Morality of Freedom, pp. 58ff.

11 See Edward S. Hinchman, "Telling as Inviting to Trust," Philosophy and Phenomenological Research 70 (2005): pp. 562-587; Paul Faulkner, "On Telling and Trusting," Mind 116 (2007): pp. 875-902; Miranda Fricker, "Group Testimony? The Making of A Collective Good Informant," Philosophy and Phenomenological Research 84 (2012): pp. 249-276. To be clear, the relational conception of authority does not depend on accepting assurance views of testimony. Further, my account is not intended to capture theoretical authority. While I am open to that possibility, it goes beyond the scope of this article, especially because issues of duty, vulnerability, and autonomy are different in the epistemic context.

12 For a similar analysis of promising, relying on implicit claims and signals, see T. M. Scanlon, What We Owe to Each Other (Cambridge, MA: Harvard University Press, 1998), pp. 306-7.

${ }^{13}$ Hinchman, p. 564.
} 
for me to utter $\mathrm{p}$ in a social condition where you require information without my utterance being intended to meet your need. If I uttered $\mathrm{p}$ as a joke, or simply as stating a random fact, it would be inappropriate. Since my utterance is directed at you in the face of your need without mitigating presentation like laughter, I am appropriately taken as signaling that this information responds to your need. I similarly signal my assurance that the information is accurate because I do not qualify my assertion, for example by stating my own doubts about the information. The nature of testimony is revealed by looking at the signals and implicit claims that any act of telling to involves.

Just as testimony is a relational act of telling to, commanding is a relational act of demanding practical deference from. ${ }^{14}$ If we only look at the conditions under which it is rational to defer, or when deference is consistent with autonomy, we miss something important about authority. It is often rational to defer to a person who does not have the standing to demand deference from us. Thus looking at the relationship itself informs us about the nature of authority in a way that asking only about responding to reasons in the abstract does not. The task of this section is to unpack the actual act of demanding another person defer to you.

The first question is what it means to defer in this context. Deferring clearly involves doing what was demanded, but this is not quite enough. Due to their illocutionary and content-independent character, commands are not just directives to act in some way; they are directives to act in some way because the commander said so. When one person exercises practical authority over another, they demand deference not to the command but to the commander. This is not deference to a good source of information or an abstract reason, but the relational deference of one person to another.

In this section I identify and discuss four salient points of interest to more fully characterize this sort of relationship. First, an authority's demand for deference is made on the basis of the subject's reasons. Second, any relationship of deference is hierarchical. Third, when a subject defers to an authority she makes herself vulnerable. Fourth, demanding deference signals that the deference is appropriate. For the sake of discussion I separate these out conceptually, but they are interwoven in a variety of important ways.

\section{A. Reasons}

First, authority is exercised within the space of reasons: commanding someone to act is clearly not identical to physically forcing them to act or threatening them. Instead, commands claim that the subject has conclusive reason to act in some way. Further, as Raz has argued, authority is based on the subject's reasons (which go beyond narrow self-

\footnotetext{
${ }^{14}$ Having the standing to demand deference from does not entail that deference is owed to the authority; I deny the "directionality thesis." See Andrei Marmor, "An Institutional Conception of Authority," Philosophy \& Public Affairs 39 (2011): pp. 238-261, at pp. 255-60.
} 
interest). ${ }^{15}$ Someone who issues commands for her own benefit and without consideration of her purported subjects necessarily lacks authority over them. Because commands make claims about subjects' reasons, issuing a command establishes a certain kind of "positive ethical relationship," in Miranda Fricker's terms. ${ }^{16}$ The ethical value present is the value of one person bending their attention, judgment, and will to the context of another and engaging the other in the space of her reasons.

Discussions of authority tend to stress the disvalue of authority relationships, especially the subject's presumptive loss of autonomy. This matters for justifying such relationships but their positive value matters for accurately characterizing and justifying them as well. Raz rightly points out that as practical reasoners, subjects should often welcome others' directives because those directives help subjects conform better to their reasons. Here we go beyond that. Initiating a relationship where one person engages another in her context and at the level of her reasons has value, as does responding to such engagement-which we will see more clearly below in the context of vulnerability.

\section{B. Hierarchy}

The next noteworthy characteristic is somewhat obvious but important to make explicit: a relationship of deference is necessarily hierarchical in nature. The hierarchy between authority and subject has been implicit throughout the discussion so far. It includes the two complementary elements of superiority and inferiority. When an authority issues a command to a subject, the command signals that the authority is in a superior position and the subject is in an inferior position. While the signal of inferiority is the more worrisome of the two, both elements require explanation.

The hierarchy is especially pressing because commands invoke the subject's own reasons. How can the subject be inferior with respect to her own reasons? How can the authority be superior with respect to someone else's reasons? Issuing a command not only sends these signals, it gives them practical import by demanding deference on the basis of the subject's inferior status in relation to her own reasons.

There are two distinct but related issues here. ${ }^{17}$ The first concerns control over one's own actions and responses to reasons: an essential part of self-determination is the standing to prioritize reasons and my responses to them. This matters for which people I choose to be friends with, my family life, my choice of profession, and so on. The other issue is about knowledge of my reasons. These are distinct: we might agree about what reasons I have but disagree about who gets to determine how I act in response to those reasons.

\footnotetext{
${ }^{15}$ Raz, The Morality of Freedom, pp. 47-48.

${ }^{16}$ Fricker, p. 252. The value of such a relationship may be utterly swamped by other considerations in particular contexts.

17 Thanks to two anonymous reviewers for pushing me here.
} 
Authorities claim superiority of both kinds: regardless of whether the subject thinks she has better judged the reasons that apply to her and regardless of whether she believes she should be the one to determine how to act, the authority claims to override her. Authority comes along with a claim not only of conformity but deference: you should not only act in some way, you should do so because you were told to. It is not only the affront of other-determination, it is other-determination on the seemingly paternalistic grounds that deference is best on the basis of the subject's own reasons.

Consider the sort of affront that appropriately follows from an unwarranted command. For example, sometimes strangers will approach cigarette smokers on the street and say, "Stop smoking!" A common response is something like "Just who do you think you are?" The strangers signal that the smoker is inferior, either lacking common information or lacking the standing to decide for herself. This naturally leads to affront. Passing strangers do not stand in the right relationship to be able to order others around and signaling the hierarchy implicit in command is inappropriate in such circumstances.

\section{Vulnerability}

Deference of any sort makes the deferrer vulnerable to the deferree, meaning that the deferrer's interests can be set back by the deferree's choices. The importance of these interests and so the degree of vulnerability varies widely across contexts. A soldier obeying a command to fight, kill, and possibly die becomes vulnerable in excruciating, fundamental ways whereas an employee obeying an order to attend a meeting becomes vulnerable much more tenuously. Of course we are all vulnerable to others in a wide variety of ways. The vulnerability of subject to authority is of a particular kind.

One way we can be vulnerable to others is when we merely rely on them. Merely relying on someone can be done without their knowledge and without any judgment of their character. Kant's neighbors may have relied on his daily walk to schedule their routines. ${ }^{18}$ They do so based on their assessment of his regularity; Kant does not know that they rely on him. Still, they are vulnerable to Kant because their own schedule may be upset if Kant fails to take his walk one day.

The vulnerability of subject to authority is much more robust than this. First, recall the reflexive intention that is intrinsic to command. Commands depend on mutual knowledge of the relationship between authority and subject because they depend on each party recognizing the authority's intention to bind in order to succeed. Unlike in the Kant case, both parties know that the subject is vulnerable to the authority. Further, the authority demands that the subject make herself vulnerable.

Both the mutual recognition of the subject's vulnerability and the demand for

${ }^{18}$ For this case, see Annette Baier, “Trust and Antitrust," Ethics (1986): pp. 231-260 at p. 235. 
vulnerability shape the relationship between authority and subject. Knowledge that someone else is vulnerable to you changes how you should act. For example, if Kant knew that others depended on the regularity of his walks, it would be reasonable for him to take a variety of new precautions to ensure regularity. The practical context of others depending on his walks is different from the context of his walks just being a personal part of his daily routine. If he (oddly) demands that they depend on his walks, then he should be especially rigorous in his schedule, should inform them if he will be off schedule, and so on. Because commands demand vulnerability, they commit the commander to recognizing and accounting for the subject's vulnerability. As Annette Baier, Fricker, and others have emphasized, we can see this by considering the appropriate response to failures: if Kant demands reliance and then fails to keep his schedule, blame and feelings of betrayal are apt, while they would not be in the unknown reliance case.

The fact that commands involve mutually recognized vulnerability shows how much it matters that deferring to authority is not just deference to an abstract source of reasons but to another person. When obeying an authority, subjects rely on another's judgment and character. ${ }^{19}$ When you defer to a command, you depend on the authority in a variety of ways: you depend on their judgment regarding your reasons, on their ability and willingness to act for those reasons, on their commitment to your autonomy and to the importance of not commanding unless necessary, and perhaps most importantly you depend on their understanding of your vulnerability and their unwillingness to exploit that vulnerability. Deferring to others creates a space where they can harm you at their discretion, so involves depending on their conscientiousness, honesty, insight, and care.

This all means that the vulnerability of subject to authority is especially relational and personal: when one person defers to another "a deal of trust is struck." ${ }^{20}$ Such deals matter: relations of trust enable and partially constitute some of the most valuable aspects of our lives. When the deal is struck, the subject signals that the authority is sufficiently trustworthy to defer to, makes herself vulnerable to the authority, the authority accepts the vulnerability that was demanded, and signals that the subject was correct to defer. ${ }^{21}$ This is why betrayal is an apt response to the abuse and misuse of authority. By deferring the subject created a space where she could be harmed by the authority, the authority accepted the subject's deference in full knowledge of that space, and in the end the subject was harmed. The deal of trust was broken.

${ }^{19}$ Cf. John Hardwig, “The Role of Trust in Knowledge," The Journal of Philosophy 88 (1991): pp. 693-708 at p. 700.

${ }^{20}$ Fricker, p. 257. Cf. Joseph Raz, "Government by Consent," in Ethics and the Public Domain (Oxford: Oxford University Press, 1995): pp. 355-369 at p. 367.

21 The authority is also made vulnerable to the subject, albeit in a notably weaker way, because her reputation is on the line, her standing as a commander and her trustworthiness are put to the test, and so on. 


\section{Appropriateness}

Finally, the command's demand for deference signals that the deference is appropriate. One way of bringing out the strength of this signal is to contrast it with the testimony case: testimony is an invitation to trust the testifier. The ultimate goal is for that invitation to be accepted, but it is still just an invitation, so is open for the recipient to accept or reject. This is akin to advice in the practical case. When I advise you to act in some way, I certainly signal that I think this is the appropriate way to act, but I am still simply inviting you to accept my advice. The ultimate standard of appropriateness is your own.

Commands are different because they demand deference. Not only do commands signal that deference is appropriate, they specifically signal that the appropriateness holds regardless of whether the subject agrees with that assessment. Commands do not invite, commands impose. If a subordinate soldier questions whether a command is appropriate, the commander's judgment of appropriateness simply overrides the subordinate's. ${ }^{22}$ Further, the command is a content-independent reason, so the appropriateness is based on the qualities of the commander rather than on the quality of the content of the command.

Commands signal that all the distinctive aspects of the relationship of authority are appropriate: that the subject really does have conclusive reason to act in the way commanded, that they should defer and thereby make themselves vulnerable, that the subject is an inferior position, that the authority is in a superior position and has the standing to accept the subject's vulnerability, that the deal of trust should be struck, and so on. The most important implication of this signal is that the commander thereby takes responsibility for the appropriateness of the relationship and its results.

It is the commander who makes the initial demand and signals appropriateness, taking the weight and implications of the relationship onto herself. When I demand that you do as I say, I put you on a path that you otherwise might not have embarked on and I rule out all other paths. In an important sense you have become an extension of my will and my understanding of how the world should be. I become responsible for your actions because I impose the relationship that led to your actions in the first place. This contrasts with the case of advice, where you might blame me for bad advice, but the ultimate responsibility is with you for accepting and acting on my advice in light of your own judgment of its quality.

Our practices of authority reflect the fact that authorities accept responsibility for their subjects' actions and the consequences of their commands. ${ }^{23}$ Military commanders are blamed for their units' failures and praised for successes, coaches are credited with their teams' wins, and so on. This is because their subordinates and players are carrying out the will of the commander by obeying the commander's directives. The commander

\footnotetext{
${ }^{22}$ On the necessary limitations of this claim, see Raz, The Morality of Freedom, p. 62.

${ }^{23}$ Responsibility is not zero-sum, so this doesn't entail that deference makes subjects less responsible.
} 
signaled the appropriateness of their subjects deferring and acting in the way commanded, so takes responsibility for their deference and its results. This goes overlooked if we focus on the rationality of subjects' deference rather than on the mutual relationship that obtains when a command is issued.

\section{Four Conditions}

The relational analysis demonstrates that the act of demanding deference from another person establishes a relationship of hierarchy, vulnerability, and responsibility. These elements are built into the nature of authority: authority is the power to command and commanding initiates and depends upon this kind of relationship. The relational conception of authority, then, asks under what conditions such a relationship is justified. In this section I argue for four individually necessary and jointly sufficient conditions on authority by showing that the authority relationship is objectionable in the absence of each.

\section{A. Duty}

Issuing a command signals that the subject is inferior specifically with respect to their reasons. Further, the signal is that they are so inferior that they should defer to the authority's judgment just because the authority said so. How could such a signal be appropriate? What would explain standing is such a relation to another person?

The most significant obstacles to such relations are our rights to autonomy and selfdetermination, which entail that we generally have the right to choose how to act within specific bounds. We get to choose how to live our lives without interference, including how to balance and prioritize our reasons, so we are aptly affronted when others arrogate to themselves the power to unilaterally interfere in such choices. Since we have a right to selfdetermination ceteris paribus, the relationship of authority does not usually obtain. There needs to be some morally weighty consideration that could defeat that right to selfdetermination. This brings me to the first condition on genuine authority:

the duty condition: a person can have authority over another only when the potential subject is under a preexisting duty, the fulfillment of which defeats standing rights to self-determination.

The latter clause recognizes the possibility that it's not the case that any duty whatsoever could ground authority. Some moral duties are relatively minor and some can only be fulfilled by self-direction; such duties will not defeat the standing right to selfdetermination.

Imagine that the duty condition is not met. If the subject is not under a duty to act (or not under a sufficiently stringent duty), then her right to self-determination holds sway 
and she should be able to choose how to live her life for herself. In general, if there is no preexisting duty, then there is nothing important enough to justify another person being in the position to demand that she act in any specific way, so nobody can have genuine authority over her. Equality defines our default relationships with others; the relationship of deference and hierarchy demands special justification.

This results in a picture of authority according to which someone only has authority for the purpose of others meeting their preexisting duties. In this way it is clearly instrumentalist: authority's purpose or role is to help subjects fulfill their duties (and correlatively respect others' rights). ${ }^{24}$ That said, the instrumentalist role of authority on the relational conception is significantly more limited than on Raz's service conception, where authority helps subjects conform better to reason generally. Practical reasons are ubiquitous for rational agents like ourselves, and so the service conception appears to license ubiquitous authority as well; but authority does not seem to extend in the ways this implies. This is the foundation of many objections to the service conception, for example grounding worries that we will be subject to the authority of reliable computers, personal trainers, cooking instructors, financial advisors, and perhaps even anyone slightly wiser than us. ${ }^{25}$

Raz does importantly limit the scope of authority with what he calls the independence condition, according to which authority only obtains when "it is better to conform to reason than to decide for oneself." 26 While Raz argues that the independence condition is an important constraint on authority, he is still concerned with the broader question of responding well to reasons and does not claim authority is limited to dutyfulfillment. He revealingly writes, "the desirability of deciding for oneself, independently of authority, is a major enhancer and qualifier of the scope of authority." 27

In contrast, on my view authority concerns when one has the right to decide for oneself, not when deciding for oneself is merely desirable. Raz mentions a case where you are unsure of your own judgment and so looking to another for guidance is desirable. According to the service conception a subject may well be under genuine authority in such cases, but not according to the relational conception. It may be desirable to let someone

\footnotetext{
24 This doesn't entail that the purpose of authority is to maximize duty-fulfillment.

25 See Perry, pp. 47, 49; Shapiro, pp. 417, 423; Darwall, "Authority and Second-Personal Reasons for Acting," pp. 147-148; Stephen Darwall, "Authority and Reasons: Exclusionary and Second-Personal," Ethics 120 (2010): pp. 257-278 at p. 258; Kenneth Einar Himma, "Just 'Cause You're Smarter than Me Doesn't Give You a Right to Tell Me What to Do: Legitimate Authority and the Normal Justification Thesis," Oxford Journal of Legal Studies 27 (2007): pp. 121-150.

${ }^{26}$ Joseph Raz, "The Problem of Authority: Revisiting the Service Conception", Minnesota Law Review 90 (2006): pp. 1003-1044 at p. 1014; also see The Morality of Freedom, p. 69.

27 Joseph Raz, "Comments and Responses," in Lukas H. Meyer, Stanley L. Paulson, and Thomas W. Pogge (eds.) Rights, Culture, and the Law: Themes from the Legal and Political Philosophy of Joseph Raz (Oxford: Oxford University Press, 2003): pp. 253-273, at p. 261.
} 
else decide, and rational to do so, but on my view you cannot be under authority because you are not under any preexisting duty-which is why personal trainers and cooking instructors lack practical authority. The rationality or desirability of deferring to someone is distinct from whether they have the power to demand deference from you.28

Similar thoughts about desirability and rights apply in other contexts. Your property rights constrain others' actions even when it is desirable or somehow rational to let them act. It might be desirable to let an interior designer into your home to decorate, yet they are only permitted to do so if you allow it. The desirability is distinct from the question of whether they have the standing to unilaterally do what is desirable.

Two further clarifications: first, as part of my attempt to provide a relatively ecumenical theory of practical authority, I leave open the particular account of duty. The relational conception shows what considerations must be balanced to understand authority, but many comprehensive value theories could employ it. Plausibly what matters is that there can only be genuine authority when some significantly important interests of others are at stake, which ground very weighty, presumptively binding reasons for us to respect those interests. Only duties could override the significant interests we have in selfdetermination, which ground our standing immunity against others having the power to command us.

Our final view about the scope and shape of genuine authority will in large part be determined by our view about the relevant duties, including how stringent they are, to what extent we owe positive duties of aid to others, and so on. Included in this will be our understanding of autonomy or self-determination and its importance relative to other grounds of duties. This affects the latter clause of the duty condition; the more important you think autonomy is, the fewer duties will be sufficiently important to override it. Robert Paul Wolff's anarchist argument could be interpreted as the end point of this spectrum, according to which deference is conceptually heteronomous. ${ }^{29}$

Second, the duty condition is quite flexible. Below I use the example of an emergency duty of aid but many other relevant kinds of duties have significantly different implications for authority. Two interesting examples: first, a Rawlsian natural duty of justice to establish and maintain the basic structure of society is a life-long and pervasive duty that has drastic implications for the possibility of genuine political authority. ${ }^{30}$ This is not like a temporary duty of aid, but a duty that may justify intergenerational institutions of authority. Second, the duty condition can be met by a duty created with an act of consent. This is particularly relevant for many of the practices of authority in our daily lives that are based on contracts, like those in an employment context. Consent is a somewhat artificial way to fulfill the duty condition: insofar as your employer has authority, it is not based on

${ }^{28}$ Cf. Perry, p. 42 and A. John Simmons, Boundaries of Authority (Oxford: Oxford University Press, 2016), p. 26.

${ }^{29}$ Robert Paul Wolff, In Defense of Anarchism (New York: Harper \& Row, 1970).

${ }^{30}$ John Rawls, $A$ Theory of Justice rev. ed. (Cambridge: Harvard UP, 1999), pp. 293-94. 
some separate duty (e.g. a duty to be maximally productive) but on the duty you create to abide by the terms you consented to.

\section{B. Precedence}

So the subject has a particularly important kind of duty, the sort that could potentially justify deference. Call it the "grounding" duty. The grounding duty only captures the first step in the possibility of justified deference and the hierarchy that such deference entails. It does not yet explain why the subject is inferior with respect to these reasons in this particular case or why the authority is superior. The duty condition establishes that deference may be required in a particular class of cases but we still need to explain why the subject should defer to a specific other person. This leads us to our second condition:

the precedence condition: a person can have authority over another only when the potential subject is more likely to fulfill her grounding duty by following the potential authority's commands than by following her own judgment.

When the authority's commands are likely superior for the relevant purposes, her commands take precedence over the subject's judgment. (This essentially amounts to Raz's normal justification thesis.) A variety of considerations can fulfill the precedence condition, including expertise, perspective, and coordination.

Consider the following case: hiking with your doctor friend in the forest far beyond the range of phone service or friendly outposts, you discover some critically injured and unconscious hikers. The motivating idea behind the precedence condition is that as you assist the hikers you should defer to your friend because her medical judgment is so superior to yours, given her expertise (without considering yet whether she has authority). Not only should you defer, it is appropriate for her to signal the superiority of her judgment and the relative inferiority of your judgment. You have an urgent task to perform and this is not the time for a friendly debate about the relative merits of various medical treatments, especially not between expert and novice.

Imagine that the precedence condition is not met, as when your hiking friend is a medical novice like you. In that case it would be odd to think that you should defer to them precisely because following their commands is no more likely to help the hikers than following your own judgment is. You still need to coordinate but neither of you is in the place to initiate a relationship of authority: to demand deference from the other, to signal superiority and inferiority, and to take the weight of the hikers' lives on your will.

Authority in an emergency is quite different from other kinds of authority. Political authority, for example, is generally claimed over wide swaths of activities and over the entire course of subjects' lives. The precedence condition will be much harder to meet in 
such cases, wherein commands signal a much more wide-ranging and fundamental relationship of hierarchy and have significant implications for subjects' standing as selfdetermining persons. But this is what we should expect. The broader the scope of an authority's jurisdiction, the less room for subjects to choose for themselves, so the heavier the justificatory burden.

\section{Acceptance}

The duty and precedence conditions account for appropriate hierarchical signals in the space of reasons. The final two conditions capture the crucial aspect of mutually recognized and unilaterally demanded vulnerability. We first focus on the standing to demand vulnerability.

Recall the deal of trust: authorities are aware that they demand deference and vulnerability from subjects, subjects recognize that demand, and subjects accede to the demand specifically on the word of the authority. In order for this to be justified, the authority must recognize and respect the subject's vulnerability and the expression of trust that deference entails. The authority recognizes the trust put in her and recognizes the fact that she signaled the appropriateness of that trust in the first place. For all these reasons the authority must account for the relationship of vulnerability in her actions by taking responsibility for the command and its consequences, including but not limited to the consequences on the subject herself. From this we get the third condition:

the acceptance condition: a person can have authority over another only when the potential authority understands and accepts that she has authority and the accompanying responsibility of command.

I lack authority over you if I do not appreciate the gravity of issuing commands to you and expecting you to carry out my will in the world. In that case I do not have the standing to demand deference from you and you are not subject to my will (even if you have reason to defer to me).

Imagine that the acceptance condition is not met. Genuine authority without the acceptance condition would entail that one person could justifiably demand deference and vulnerability from another without any recognition of the costs of her commands for her subjects or the gravity of the relationship she is initiating. She would not appreciate the trust put in her and would not take account of the subject's vulnerability in her deliberations about how to exercise, and not exercise, her authority. In not understanding the costs of deferring to an authority, she also does not understand the risks of abusing authority by making inappropriate demands. The idea that she could have genuine authority in such conditions undercuts the instrumentalist role of authority and contradicts our practices of authority, wherein authorities take responsibility for their role and can 
lose their authority when they act irresponsibly.

The acceptance condition is one of the most distinctive elements of the relational conception. Discussions of authority generally focus on the conflict between autonomy and authority, which is a conflict for subjects. As such the role of the authority has been comparatively ignored. What the relational analysis shows is that subjects defer in large part because of authorities' commitments and signals that accompany any command, importantly including the authority's commitment to accept responsibility for the relationship. ${ }^{31}$ A social practice of authority that relied on subjects responding to an authority's implicit acceptance of responsibility but did not require the authority to actually accept responsibility would be unreasonable.

Two notable results: first, someone who was otherwise well placed to be an authority might lack authority because she refuses to take responsibility. Second, the acceptance condition emphasizes that authorities need some understanding of the nature of command. In the injured hikers case the potential authority at stake is very limited in both scope and time and your doctor friend presumably recognizes the impermissibility of demanding deference from you in normal contexts. But in other cases, again highlighting the political case where governments not only claim vast authority but set the limits of their own authority and coercively enforce it, it is incredibly important that governments understand the nature of authority and its costs. Agents that do not recognize what is at stake in a relationship of authority cannot stand in such a relationship over others and so lack genuine authority.

This is true even if it would be good or required for subjects to defer to their directives on other grounds and so the first two conditions were met. For example, a government that does not recognize its responsibilities to citizens in issuing commands lacks political authority. Citizens may still be required to conform to particular laws, for example following guidelines on the storage of industrial chemicals, but this requirement is grounding in the fact that the law is a good guide to what counts as sufficiently secure storage, not because the government can appropriately demand deference. As emphasized above, the requirement and the standing to impose the requirement are distinct.

There is a worry here, however. It may seem that, rather than a condition on genuine authority, the acceptance condition describes something extraneous, such as a duty of care or virtuous command.32 However, many relationships-and the powers and claims conferred by being in such relationships-are contingent on the acknowledgement and acceptance of various rights and responsibilities. The powers that parents have over their children are in part contingent on accepting a duty of care; if the parent abuses the child and so egregiously fails the duty of care, they lose the powers of parenting. We think such powers are contingent on accepting the duty of care due to the interests of the child,

\footnotetext{
${ }^{31}$ Cf. Scanlon, p. 307.

32 Thanks to three anonymous reviewers for raising this issue.
} 
the nature of the relationship, and how we understand the social practice of parenting. The same is true of authority. Possessing the power to demand deference is contingent on accepting the responsibilities of command because deference requires that subjects make themselves vulnerable.

In both the authority and parenting cases, the minimal responsibility upon which possession of the power is contingent is also clearly distinct from the standards defining a virtuous relationship. A virtuous parent goes far beyond refraining from neglect or abuse and a virtuous authority would go beyond refraining from abusing her authority. The acceptance condition marks out a minimal prerequisite for possession of authority, not anything more robust.

\section{Trustworthiness}

Deferring to an authority makes the subject vulnerable to the authority in the specific sense that the subject takes the mere fact of the authority's say-so as a binding reason to act, so the subject's interests may be set back by the authority choosing to direct the subject in one way rather than another. Deference involves entrusting one's interests to another. In order for such an act to be justified, the person gaining control over the interests must be sufficiently trustworthy, given the importance of the interests at stake. According to the analysis of trustworthiness that I follow, someone is trustworthy if they are sufficiently competent and are sufficiently committed to acting for the right reasons. ${ }^{33}$

Imagine you are planning to entrust your infant to a babysitter. You should do so only if the babysitter is sufficiently competent and sufficiently committed to securing your child's welfare. Lacking either makes them untrustworthy and so makes entrusting your infant to their care inappropriate. If you have a sibling who is absolutely committed to your child's welfare but is absolutely incompetent with respect to infant care, then they are untrustworthy as a babysitter. Similarly, a skilled babysitter who was your enemy and wished your child harm would not be sufficiently trustworthy. In both cases entrusting your child's welfare to them is unjustified because you should not make yourself and your child vulnerable to their decisions given their untrustworthiness: if you give them the discretionary control that entrusting entails, they are likely to set back your child's interests, perhaps disastrously.

Deference requires trustworthiness because deference entails entrusting important interests to another and to their choices, opening a space where they can harm you at their discretion. This directs us to the fourth condition:

the trustworthiness condition: a person can have authority over another only

\footnotetext{
33 This is a modified version of Baier's account of trust. See Fricker, pp. 256-7 for the modification.
} 
when the potential authority is sufficiently trustworthy relative to how vulnerable the potential subject would become by deferring.

The competence component of trustworthiness is relatively straightforward. ${ }^{34}$ The commitment component of trustworthiness is more distinctive. Even if someone is supremely competent and understands the role of authorities, if she lacks a commitment to the right reasons then she can undermine and otherwise set back your interests in a variety of ways. 35

Consider the injured hikers case with the modification that your hiking partner is a doctor primarily interested in studying hiking injuries. The doctor is committed to the wrong reasons, to research rather than assistance, so you should not defer to their commands. Even if the doctor claims they are assisting, their commitment to the wrong reasons gives you sufficient grounds to reject their demand for deference. The most you should do is examine the plausibility of their imperatives with your own judgment, keeping a wary eye out for misleading directives. In that case you would not be deferring to them as a genuine authority but merely gleaning information from them as a potentially reliable guide to your reasons.

Imagine that the trustworthiness condition is not met. Then the subject would be under the control of someone who is likely to abuse their power, whether due to incompetence, to ill-will, or to commitment to the wrong reasons. In any of these cases the purpose and role of authority would again be stymied. We would be unreasonably requiring people to make themselves vulnerable in cases where such vulnerability is both risky and ineffective.

We now have the entire relational conception of authority before us. When the four conditions are met, the appropriateness of the relationship between authorities and subjects can be explained and the various signals and commitments that commands involve can be justified. In such circumstances, one person has genuine practical authority over another because the subject is under a duty, the authority's commands take precedence over the subject's judgment in the fulfillment of that duty, the authority understands and accepts the accompanying responsibility, and the authority is sufficiently trustworthy for the subject to make herself vulnerable by deferring to the authority's will.

Consider the original hikers case. As seems clearly correct to me, your doctor friend has genuine authority over you because 1) you have a duty to medically aid the hikers, 2)

\footnotetext{
${ }^{34}$ Competence goes beyond the precedence condition because it includes elements about the actual activity of issuing commands to achieve certain ends. If someone could not make the content of their commands comprehensible, for example, they would be incompetent, even if their judgment in that domain was superb.

35 Two sets of reasons are relevant: the subject's reasons regarding fulfillment of her grounding duties and the authority's reasons regarding the possession and exercise of a power. The precedence and trustworthiness conditions concern the former, while the acceptance condition concerns the latter.
} 
she is an expert on the medical reasons, 3) she accepts responsibility for your deference, and 4) she is sufficiently trustworthy. The thought is very simple: you must do what she says regardless of your judgment on the matter because people's lives are at stake and she is a well-meaning doctor. Medical doctors have practical authority over laypeople in medical emergencies ceteris paribus.

Returning to the concept of authority, we can see how the conditions relate to preemption and content-independence. The duty and precedence conditions help explain preemption: the authority's command takes on the force of the grounding duty and so preempts reasons in conflict with that duty, while it preempts the subject's alternative possible avenues for fulfilling that duty due to the command taking precedence. The acceptance and trustworthiness conditions help explain content-independence: the subject's reason to obey is based on the authority's commitment to the subject's reasons, acceptance of the responsibility of command, and trustworthiness. It is features of the speaker and not the content of the speech act that explain how the command binds and why the subject should defer.

\section{Assessing the Relational Conception}

The advantages of the relational conception of authority are best seen in comparison to the service conception. While the main differences rest in the way the relational conception treats the authority, and so in the acceptance and trustworthiness conditions, the duty condition matters as well. We can see all three at work in the case of consent-based authority. Raz denies that consent can ground genuine authority without the service conception being met otherwise; consent is only an "auxiliary" or "secondary" consideration on his view. ${ }^{36}$ This is puzzling in the context of contemporary political philosophy, where consent is widely considered the ideal ground of genuine authority.

Raz's dismissal of consent is a direct result, though, of his focus on the general question of the rationality and desirability of deference. Consent makes little difference to these questions. You should only consent to defer where there are already weighty reasons indicating that deference is rational or desirable, so it is already the case that the service conception applies. By contrast, focusing on who has the right to decide, as in the duty condition, is quite different. Because consent can create a duty where none existed, consent can create the context for the duty condition to be fulfilled where it would not otherwise. On the relational conception consent can independently ground authority.

The acceptance and trustworthiness conditions mark the limits of consensual authority. You can consent to make someone an authority over you where such consent is imprudent. But if they ignore the limits of authority, for example by commanding you to

${ }^{36}$ Raz, "Government by Consent” and The Morality of Freedom, p. 93. 
commit murder or suicide, they fail the acceptance and trustworthiness conditions. Although consent makes these conditions less stringent because they are in part based in the reasons that you waived when you consented to obey, they do not fall out of the analysis. Reasons that you did not and could not waive, such as those regarding others' right to live, still constrain the authority and determine whether she counts as committing to and responding to the right set of reasons. In sum, Raz's mishandling of consent-based authority arises from his strict focus on how the subject should respond to reasons. By taking a more complete view, the relational conception not only accommodates but illuminates the possibility of consent-based authority.

I have gestured at this comparison to Raz throughout my discussion, but now I can state it clearly. Raz analyzes authority through the frame of the subject's problems, i.e. the rationality of deference and its compatibility with autonomy. This narrow frame results in the service conception's thin set of normative conditions on authority, which in turn makes authority too easy to achieve and so finds authority in many places where there is merely good reason to use an outside source for guidance in making decisions. I began with a wider frame by inquiring into the relationship that obtains when one person demands practical deference from another. This encompasses the subject's problems but adds two important general elements. First, the authority has her own set of problems because she is demanding another person make themselves vulnerable to her and so must accept the weighty responsibility of command. Second, the subject's position is shaped by her vulnerability as much as by the desirability of deference; her reason to defer is based in significant part on the authority's signal that the demand for deference is appropriate and on the accompanying signals of responsibility and trustworthiness. These general elements led us to the four conditions on authority, which both amend and extend the service conception. Authority does not appear whenever it is more desirable to defer to another; it is constrained to circumstances where one person stands in the appropriate relationship to demand deference from another.

Finally, while the relational analysis focuses on interpersonal features of authority, I intend the relational conception to capture all kinds of practical authority, importantly including political authority. A potential objection rests precisely in this individual orientation: authority is most often institutional in our world and it is unclear whether the relational conception explains authority in that context.

There are two worries here. First, it may appear as if I am claiming that institutional authority rests on the characteristics of individuals: on whether individuals within the institution are sufficiently trustworthy, accept the responsibilities of command, and so on. But this is implausible because, first, institutions can mask or change individual characteristics. More fundamentally, as Scott Shapiro argues, "Because the legitimacy of an official's authority is impersonal, dependent as it is on the legitimacy of the office, the 
personal qualities of any official can contribute nothing to the legitimacy of the official's authority." 37

Nothing I argued above commits me to the view that institutional authority must rest in the characteristics of individuals. The relational conception takes the institutional whole as its evaluand because that is where institutional authority ultimately rests. The authority of any given official is best understood as delegated from the institutional whole. My conditions on authority regard possession, not necessarily delegation. For example, trustworthiness is necessary for genuine authority but a particular bureaucrat need not be individually and personally trustworthy for her to have the authority conferred by her office. Rather, the whole system from which she received her delegated authority must be sufficiently trustworthy (including the rules that regulate delegation and ensure individual office-holders do not abuse their positions). The picture is more complex at the level of institutions but the same conditions hold. ${ }^{38}$

This raises the second worry: what features of the institutional whole do we evaluate when applying the conditions? Consider trustworthiness again, analyzed in terms of competence and commitment to the right reasons. Individual trustworthiness is usually assessed via character traits: "She's a reliable person, with a good heart." It's not clear what it means for an institution to be trustworthy in the same way since institutions seem not to have character traits in the same way that individuals do.

However, we commonly ascribe similar character traits to institutions, understood mainly through the lens of institutional design. Competence should be fairly clear; we need to assess institutional competence to apply the service conception as well. When the Environmental Protection Agency employs scientific experts, institutional design enables that expertise to shape its directives. We can tell a complicated story about how various scientists, administrators, and so on are employed by the agency and form a cohesive whole through institutional rules and norms. This would explain how under the right conditions the institution's directives can constitute sufficiently competent, even expert, directives.

Commitment to the right reasons can similarly be constituted by institutional accountability mechanisms rather than by personal beliefs or virtues. In the case of political institutions, constitutions set out what sorts of reasons the government can act upon and which it can't. They set constraints on the exercise of political power, for example through a bill of rights. Effective institutional design and healthy institutional culture can partially constitute commitment to the right reasons.

\footnotetext{
${ }^{37}$ Shapiro, p. 401.

38 Any theory of authority will need to make this general move because commands conceptually require a specific intention yet an official within an institution may unintentionally exercise authority, e.g. accidentally stamping an order. The relevant intentionality must exist at the level of the institution as determined by institutional rules, not by individual office-holder mental states.
} 
Related thoughts show how to apply the acceptance condition. Governments recognize the weight of their responsibility and the difficulty of exercising authority well and so take strides to make their reasons explicit, their self-acknowledged responsibilities clear, and their accountability mechanisms strong and public. They do this in part through institutional design-constitutions, the separation of powers, checks and balances, etc.but also through norms of transparency, public justifications, and so on. Note that the responsibility of political authorities is extremely weighty, largely because failures can be so disastrous, so what it means to sufficiently understand and accept the responsibility of command will be much more demanding than in cases like the emergency authority described above. However, the general idea that plausible claimants to genuine political authority must meet stringent demands of this sort in their institutional design and culture is already widely accepted. The relational conception helps explain why we think governments that lack these features cannot have genuine political authority.

In conclusion, practical authority exists to help people better fulfill their duties and meet people's claims. To have authority, though, is to have the power to demand practical deference from others, and this power is worrying both to wield and to be subject to. Analyzing the relationship that obtains when such a power is exercised led me to the relational conception of authority. Only if the duty, precedence, acceptance, and trustworthiness conditions are jointly met does one person have genuine practical authority over another. 